Original Article Received/Accepted Dates

08.12.2021/20.02.2021

DOI 10.52096/usbd.6.24.3
International Journal of Social Sciences

Uluslararası Sosyal Bilimler Dergisi

www.sobider.net
ISSN: 2548-0685

\title{
Analysis of Morphological Shifts Gender and Number Shift Observed in the Translation of the Holy Qur'aan from Arabic into Amharic
}

\author{
Ph.D. Mohammed Miftah \\ Addis Ababa University \\ Linguistics \\ miftahm84@gmail.com
}

\begin{abstract}
In this article, morphological shifts, number and gender shits observed in the translation of the Holy Qur'aan from Arabic into Amharic have been discussed and analyzed. Shifts in agreement in number and gender between parts of a sentence have been discussed. From the discussion given in the article one can conclude that agreement in number and gender is sensitive to word order in Arabic. For example, when the subject follows the verb the suffixes that show agreement are absent, but they are obligatorily present if the subject precedes the verb. Therefore, sometimes agreement in number and gender may not be strict in Arabic. However, in Amharic there should always be strict agreement in gender and number. Therefore shifts in number and gender have been obligatorily made by the translators of the Holy Qur'aan from Arabic into Amharic to produce grammatical sentences in the target language structure. However, in some instances, as discussed in the article, the translators closely adhered to the source language structure which produced ungrammatical or unknown structures in the target language structure. This may make some structures in the target text incomprehensible.
\end{abstract}

Key Words: Source text, target text, target language structure, morphological shifts, gender and number Shift

\section{Introduction}

The main objective of this article is to identify and describe morphological shifts such as gender, number, shifts that have been observed in the translation of the Holy Qur'aan from Arabic into Amharic. 
Gender and number shifts may be observed in the translation of a word from the source language to the target language. For example, when a singular verb is translated from the source language to the target language it may be changed to plural verb. A dual verb or noun may be translated as plural ones. A feminine verb or noun may be translated without making any distinction between masculine and feminine. These types of number and gender shifts are technically referd to as intrasystem shifts (Catford ,1965:80). Therefore, this article describes and discusses these types of shifts in detail using data from both the source and the target texts.

\section{Gender and number shifts in the translation of the Holy Qur'aan from Arabic into Amharic}

Various types of shifts in agreement in gender and number between parts of a sentence have been observed in the translation of the Holy Qur'aan from Arabic into Amharic. These shifts have been analyized and discussed below in detail.

(a) The shift from a masculine and singular verb + a feminine by form and singular subject in Arabic into a masculine and singular subject + a masculine and singular verb in Amharic

1. ST: :

$$
\begin{aligned}
& \text { qad kaana la-kum Paayat-un } \\
& \text { already be.PRV PRE-2MPL sign.FSG-NOM }
\end{aligned}
$$

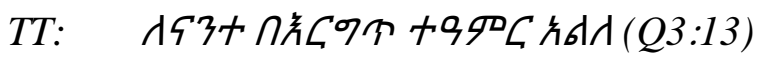

$$
\begin{gathered}
\text { la-innanta bairgit' toวammir Pall-ə } \\
\text { PRE-2PL indeed sign be.PRF-3MSG }
\end{gathered}
$$

TR: Already there has been for you a sign (Q3:13)

The example given above (1) illustrates that the sentence in the source text used a masculine and singular verb كَانَ(kaana/) which means 'has been' followed by a feminine by form and singular subject 
singular verb preceded by a masculine and singular subject $\hbar_{6} /$ (/Pall-ə/) and $+99^{\circ} C$ (/tə?mmir/) which means 'has been and sign' respectively.

The above data (1) show that in the source text (Classical Arabic) if the subject of a sentence is feminine only by form its preceding verb may be put in a masculine form. Therefore, in that case, there may not be a strict agreement in gender between the subject and the verb. However, in the target text (Amharic), there is strict agreement in gender between the subject and the verb. This shows that the translators of the Holy Qur'aan from Arabic into Amharic employed gender shift to keep the grammar of the target text

(b) The shift from a masculine and singular verb + a feminine and plural subject in Arabic into a plural subject + a plural verb in Amharic

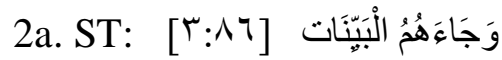

wa dзaa?a-humu ?al-bayyin-aat-u CONJ come.PRF-OBJ3MPL DEF-verse/sign-FPL-NOM

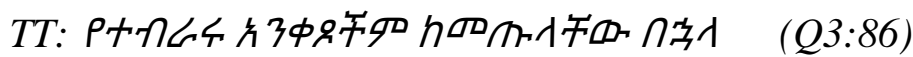

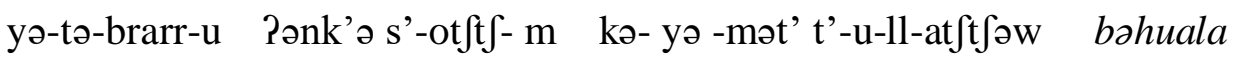

REL-PASS- clear-3L verse/sign-PL-CONJ PRE-REL-com.PRF-3PL-BEN-3PL PRE

TR: and clear signs had come to them (Q3:86)

The example given above (2a) illustrates that the sentence in the source text used a masculine and singular verb جَاءَ(/dzaa?a/) which means 'had come' followed by a feminine and plural subject الَبِينَاتُ (Ral-bayyin-aat-u/) which means 'clear signs/verses'.However, the target text used a plural

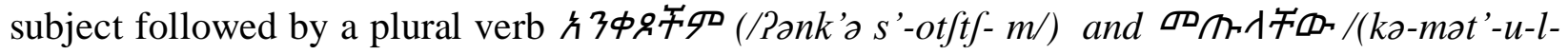
at/t/aw/) which mean 'clear signs/verses' and 'had come for them' respectively.

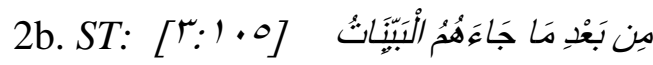

min baSd-i maa dzaa?a-hum Pal-bayyin-aat-u 


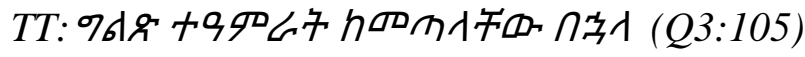

gìls' toramr-at ka-mam t' t'a-ll-atftjaw bahuala

clear proof-PL PRE-come.INF-BEN-3PL PRE

TR: after the clear proofs had come to them (Q23:105)

The example given above (2b) illustrates that the sentence in the source text used a masculine and singular verb (َ) / / Jaa?a/) which means 'had come' followed by a feminine and plural subject الَبِينَاتُ (2/Pal-bayyin-aat-u/) which means 'clear signs' while the target text used a plural subject followed by a singular verb † † which mean 'clear signs' and 'had come' respectively. There is no agreement in number in the Amharic sentence. Such a sentence construction violets the Amharic grammar rule though Amharic is strict in number agreement between the subject and the verb.

The above data (2a) shows that in the source text (Classical Arabic) if the subject of a sentence is feminine and plural, its preceding verb may be put in a masculine and singular form. Therefore, in that case, there may not be a strict agreement in gender and number between the subject and the verb. However, in the target text (Amharic), there is strict agreement in gender between the subject and the verb. This shows that the translators of the Holy Qur'aan from Arabic into Amharic employed gender and number shift to keep the grammar of the target text. However, in ( $2 \mathrm{~b})$, the translators employed plural subjects with singular verbs in the target text though not allowed. This shows sometimes the translators adhere to the source language structure and violate the target language structure.

(c) The shift from a feminine and singular verb + a feminine and plural subject in Arabic into a plural subject + a plural verb in Amharic

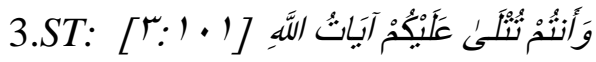

wa Pantum t-u-tlaa Salay-kum Paay-aat-u Pallah-i 
IJSS, 2022, Volume 6, Issue 24, p. 36-59.

\section{CONJ you.MPL 3F-PASS-recite PRE-2MPL verse-FPL-NOM Allah-GEN}

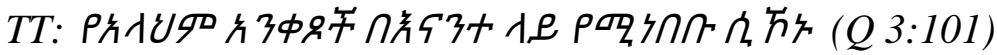

$$
\begin{aligned}
& \text { yə-Pallah-m Ponk'əs'-otft } \quad \text { bə-innanto lay } \\
& \text { POSS-Allah-CONJ verse-PL PRE-you.PL PRE } \\
& \text { уәт- yi-nпวbаb-u s-yi-hon-u } \\
& \text { REL-3-recite.PASS.IPFV-PL REL-3-COP.IPFV-PL }
\end{aligned}
$$

TR: while to you are being recited the verses of Allah (Q3:101)

The example given above (3) illustrates that the sentence in the source text used a feminine and singular verb iُ (1/t-u-tlaa/) which means 'is being recited' followed by a feminine and plural subject آتَاثُ (/Paay-aat-u/) which meansn' the verses' while the target text used a plural subject

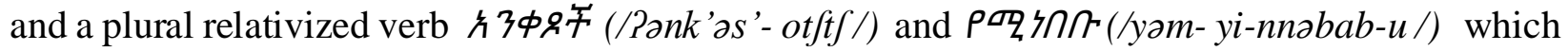
mean 'verses' and 'that are recited' respectively.

All the above data (3) show that in the source text (Classical Arabic) if the subject of a sentence is feminine and plural, its preceding verb may be put in a feminine and singular form. Therefore, in that case, there may not be a strict agreement in number between the subject and the verb. However, in the target text (Amharic), there is strict agreement in number between the subject and the verb. That is, the target text used a plural subject and a plural verb .This shows that the translators of the Holy Qur'aan from Arabic into Amharic employed gender and number shift to keep the grammar of the target text.

(d) The shift from a masculine and singular verb + a masculine and plural subject in Arabic into a plural subject + a plural verb in Amharic

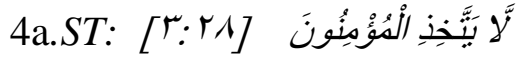

laa ya-ttaxið- $\varnothing \quad$ ?al-mu?min-uuna 


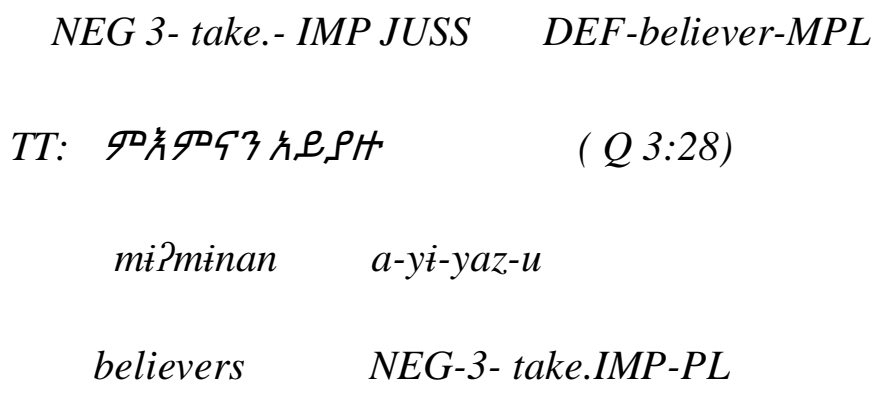

TR: Let not believers take

$(Q 3: 28)$

The example given above (4a) illustrates that the sentence in the source text used a masculine

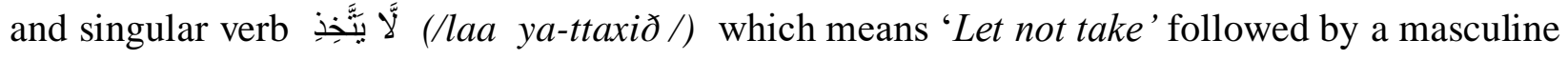
and plural subject ألْدُوْينُونَ (/Pal-muPmin-uuna/) which means 'believers'.

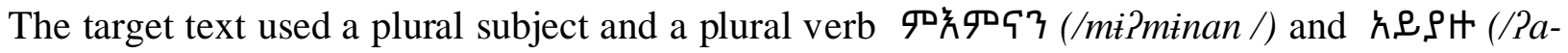
yi-yaz-u /) which mean 'believers' and 'let not take' respectively.

All the above data (4a) show that in the source text (Classical Arabic) if the subject of a sentence is a masculine and plural, its preceding verb must be put in a masculine and singular form. Therefore, in that case, there may not be a strict agreement in number between the subject and the verb. However, in the target text (Amharic), there is strict agreement in number between the subject and the verb. That is, the target text used a plural subject and a plural verb .This shows that the translators of the Holy Qur'aan from Arabic into Amharic employed gender and number shift to keep the grammar of the target text.

(e) The shift from a feminine and singular verb + a broken plural subject in Arabic into a plural subject + a plural verb in Amharic

5a.ST: [r:

f-anada-t-hu Pal-mala?ikat-u

CONJ-call.PRF-SBJ3FSG-OBJ3MSG angels-NOM

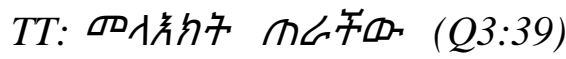

mala?kt t'rra-t/tfi-w 


$$
\text { angels call.PRF-SBJ3FSG-OBJ3MSG }
$$

TR: So the angels called him (Q3:39)

The example given above (5a) illustrates that the sentence in the source text used a feminine and singular verb فَنَادَنُُْ (/f a-anada-t-hu /) which means 'called him' followed by a broken plural

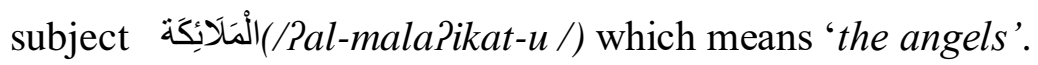

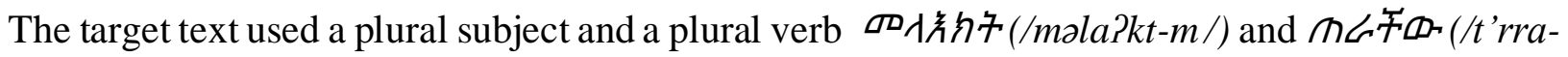
$t f t / \hat{t}-w /)$ which means and 'angels' and 'she called him' respectively.

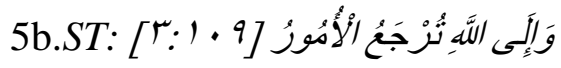

$$
\text { wa-Pilaa Pallaah-i t-u-rjas-u ?al-?umuur-u }
$$

CONJ-PRE Allah-GEN 3FSG-PASS-return.IPFV-IND DEF-matters-NOM

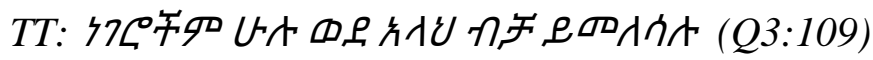

nagar-otftf-m hullu wado Pallah bitfta yi-mmalasall-u

matter-PL-CONJ all PRE Allah only 3-return. PASS IPFV-3PL

TR: And to Allah will [all] matters be returned. (Q3:109)

The example given above (5b) illustrates that the sentence in the source text used a feminine and singular verb تُزْجَعُ (/t-u-rjaS-u/) which means ' will be returned' followed by a broken plural subject الُُْمُورُ (/Pal-?umuur-u/) which means matters.

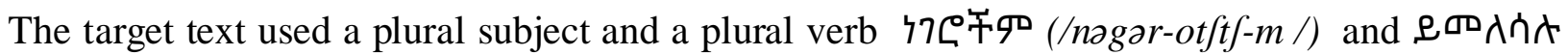
(/yi-m-malosal-u/) which means 'and matters' and 'will be returned' respectively.

The above data (5b) show that in the source text (Classical Arabic) if the subject of a sentence is a broken plural, its preceding verb may be put in a feminine and singular form. Therefore, in that case, there may not be a strict agreement in number and gender between the subject and the verb. However, in the target text (Amharic), there is strict agreement in number and gender between the subject and the verb. That is, the target text used a plural subject and a plural verb. This shows that 
the translators of the Holy Qur'aan from Arabic into Amharic employed gender and number shift to keep the grammar of the target text. However, in (5a), the translators employed plural subject

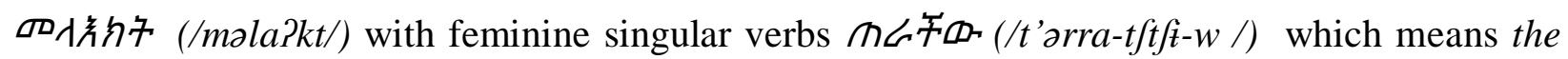
angles and called him in the target text though such is not allowed. This shows that sometimes the translators closely adhere to the source language structure and violate the target language structure.

( f) The shift from a masculine and singular verb + a broken plural subject in Arabic into a plural subject + a plural verb in Amharic

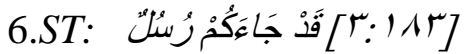

qad dzaa?a-kum r`usul-un

already come.PRF-OBJ2MPL messengers.PL-NOM

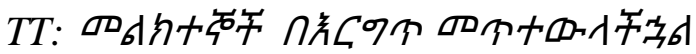

$(Q 3: 183)$

malktan- otft bargit' mat'ita-u-l-at/tfîhu-al

messenger-PL already come.PRF-SBJ3PL-BEN-2PL-T

TR: There have already come to you messengers

The example given above (6) illustrates that the sentence in the source text used a masculine and

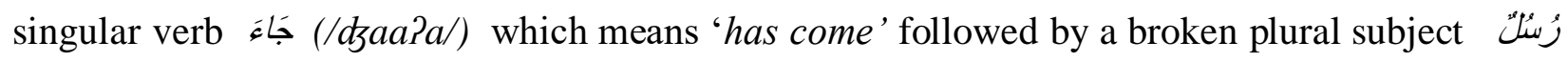
(/rusul-un /) which means 'messengers'.

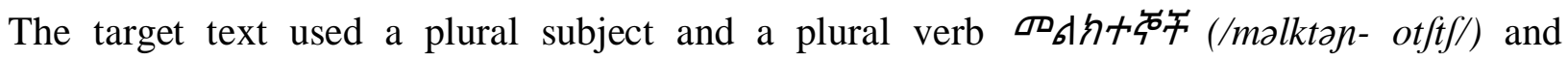

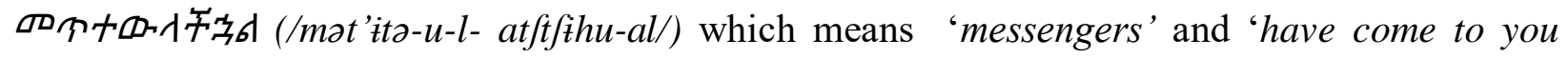
'respectively.

The above data (6) show that in the source text (Classical Arabic) if the subject of a sentence is a broken plural, its preceding verb may be put in a masculine and singular form. Therefore, in that case, there may not be a strict agreement in number and gender between the subject and the verb. However, in the target text (Amharic), there is strict agreement in number and gender between the 
subject and the verb. That is, the target text used a plural subject and a plural verb. This shows that the translators of the Holy Qur'aan from Arabic into Amharic employed gender and number shift to keep the grammar of the target text

(g) The shift from a masculine and singular verb + a collective noun subject in Arabic into a plural subject + a plural verb in Amharic

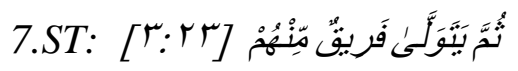

Oumma ya-tawalla fariiq-un min-hum

CONJ 3MSG- turn away.IPFV a party-NOM PRE-3MPL

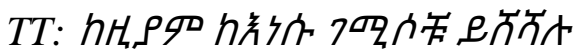

kaziyam kə-innəsu gamis- otftf-u yi-fof-al-u

CONJ PRE-them party-PL-DEF 3- turn away.IPFV-T-3PL

TR: then a party of them turns away $\quad(Q 3: 23)$

The example given above (7) illustrates that the sentence in the source text used a masculine and

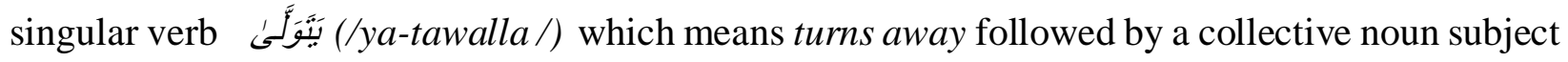
فَرِيٌُ (/fariiq-un/) which means a party.

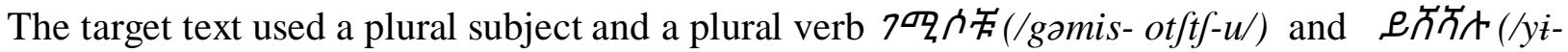
$\left.\int \partial-a l-u /\right)$ respectively.

The above data (7) show that in the source text (Classical Arabic) if the subject of a sentence is a collective noun, its preceding verb may be put in a masculine and singular form. Therefore, in that case, there may not be a strict agreement in number and gender between the subject and the verb. However, in the target text (Amharic), there is strict agreement in number and gender between the subject and the verb. That is, the target text used a plural subject and a plural verb.

(h) The shift from a feminine and singular verb + a collective noun subject in Arabic into a plural subject + a plural verb in Amharic 


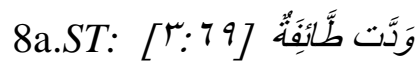

wadda-t t $t^{\varsigma}$ aaPifa-t-un

wish.PRF-F A faction-F-NOM

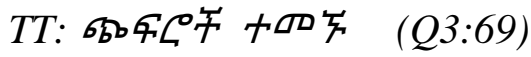

tf'ifr- otft taman-u

faction-PL wish.PRF-3PL

TR: A faction wish (Q3:69)

The example given above (8) illustrates that the sentence in the source text used a feminine and singular verb (1/wadda-t/) which means 'wished' followed by a collective noun subject (/t'aaPifa-t-un /) which means 'a faction'.

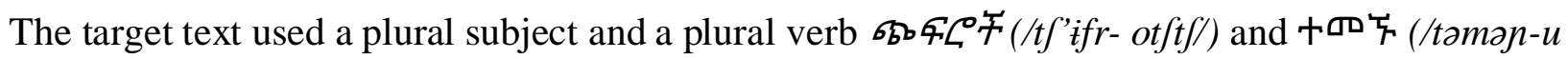
/) which mean 'factions' and 'wished' respectively.

The above data (8) show that in the source text (Classical Arabic) if the subject of a sentence is a collective noun, its preceding verb may be put in a feminine and singular form. Therefore, in that case, there may not be a strict agreement in number and gender between the subject and the verb. However, in the target text (Amharic), there is strict agreement in number and gender between the subject and the verb. That is, the target text used a plural subject and a plural verb.

(i) The shift from a feminine and singular verb + a feminine dual subject in Arabic into a plural subject + a plural verb in Amharic

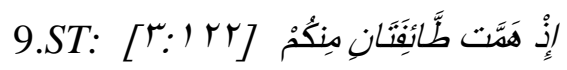

Рið hamma-t t'aa?ifa-t-aani min-kum

When incline.PFV-F party-F-DU.NOM PRE-2MPL

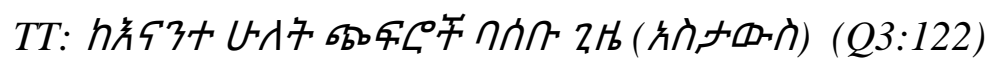


ka innanta hulat tf'iffr-otft for-Pasab-u gize(Pastaws)

PRE you.PL two party-PL when-think.PRF-PL when(remember)

TR: When two parties among you were about to lose courage (Q3:122)

The example given above (9) illustrates that the sentence in the source text uses a feminine and singular verb إِدْ هَمَّت (/Pið hamma-t/) which means 'when thought' followed by a dual collective

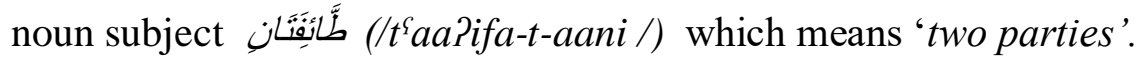

The target text uses a plural subject and a plural verb Uイ市 2/b (/ba-?asab-u gize /) which means 'two parties' and 'when they thought' respectively.

The above data (9) shows that in the source text (Classical Arabic) if the subject of a sentence is a feminine and dual noun, its preceding verb may be put in feminine and singular form. Therefore, in that case, there may not be a strict agreement in number between the subject and the verb. However, in the target text (Amharic), there is strict agreement in number and gender between the subject and the verb. That is, the target text used a plural subject and a plural verb. This shows number shift.

(j) The shift from a masculine and singular verb + a masculine and dual subject in Arabic into a plural subject + a plural verb in Amharic

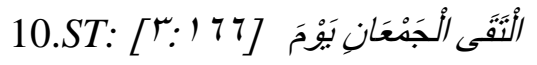

yawma Piltaqaa Pal-dzams-aani

day meet.PRF DEF-army-DU.NOM

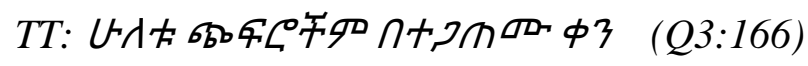

hulat-u t'iffr-otftf-m ba-tagat'm-u k'on

TR: on the day the two armies met (Q3:166) 
The example given above (10) illustrates that the sentence in the source text used a masculine and singular verb الْنَقَى (/Piltaqaa/) which means met followed by a dual noun subject dzamS-aani /) which means 'two parties or two armies'.

The target text used a plural subject and a plural verb UAћ

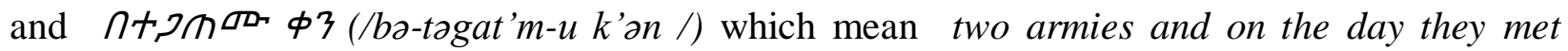
respectively.

The above data (10) show that in the source text (Classical Arabic) if the subject of a sentence is a masculine and dual noun, its preceding verb may be put in a masculine and singular form. Therefore, in that case, there may not be a strict agreement in number between the subject and the verb. However, in the target text (Amharic), there is strict agreement in number and gender between the subject and the verb. That is, the target text used a plural subject and a plural verb. This shows number shift

(k) The shift from a broken plural noun + a feminine and singular adjective in Arabic into a plural adjective or relativized verb + a plural noun in Amharic

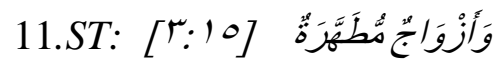

wa Pazwaadz-un mut ahhara-t-un

CONJ spouses-NOM purified-F-NOM

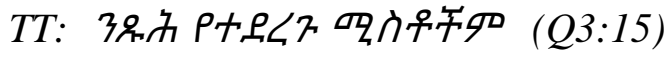

nis'uh yə-tว-darag-u mist- otftf-m

pure REL-PASS-make. PRF-PL spouse-PL-CONJ

TR: and purified spouses $\quad$ (Q3:15)

The example given above (11) illustrates that the noun phrase in the source text used a broken plural noun adjective مُّطََّرَة 
The above data (11a ) show that in the source text (Classical Arabic) if the noun of a noun phrase is a broken plural noun, its following adjective may be put in a feminine and singular form. Therefore, in that case, there may not be a strict agreement in number between the noun and its adjective. However, in the target text (Amharic), there is strict agreement in number and gender between the noun and its adjective. That is, the target text used a plural noun and a plural relativized verb. This shows number shift.

1) The shift from a broken plural noun + a feminine and singular complement in Arabic into a plural noun+ a plural complement in Amharic

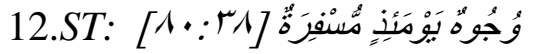

wudzuuh-un yawma?ið-in musfira-t-un faces-NOM that day-GEN bright-F-NOM

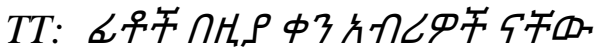

(Q80:37)

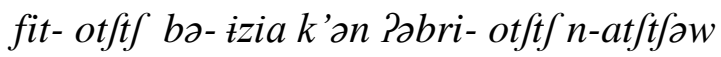

face-PL PREDEM day bright-PL COP.PRF-3PL

TR: [Some] faces, that Day, will be bright

$(Q 80: 37)$

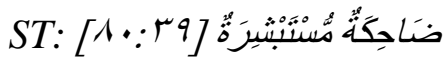

$d^{\complement} a a \hbar i k a-t-u n$ mustabfira-t-un

Laughing-F-NOM rejoicing-F-NOM

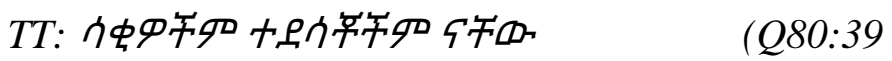

sak'i-otftf - m todəsatf-otftf-m n-atftfow

Laughing-PL-CONJ rejoicing-PL-CONJ COP.PFV-3PL

TR: Laughing, rejoicing at good news (Q80:39) 
The example given above (12) illustrates that the nominal sentence in the source text used a broken plural noun وُجُوهُ (/wudzuuh-un /) which means faces followed by a feminine and singular

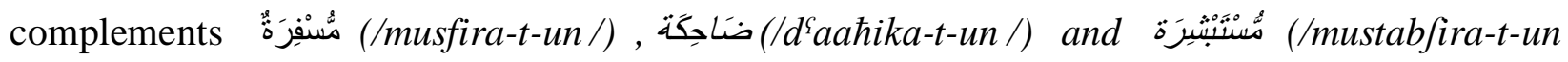
/) which mean 'bright', Laughing and 'rejoicing at good news' respectively. The target text used

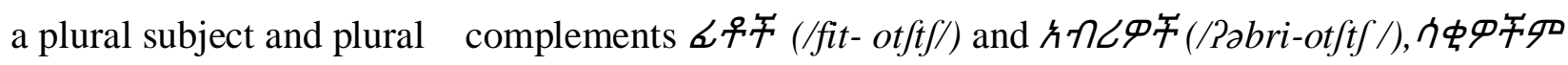

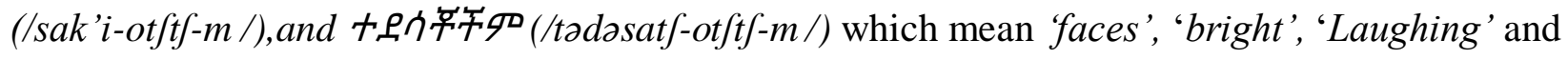
'rejoicing at good news' respectively.

The above data (12) shows that in the source text (Classical Arabic) if the subject of a nominal sentence is a broken plural noun, its complement may be put in a feminine and singular form. Therefore, in that case, there may not be a strict agreement in number between the noun and its complement. However, in the target text (Amharic), there is strict agreement in number and gender between the noun and its complement. That is, the target text used a plural noun and a plural complement. This shows number shift.

(m) The shift from a broken plural noun + a feminine and singular verb in Arabic into a

plural relativized verb + a plural noun in Amharic

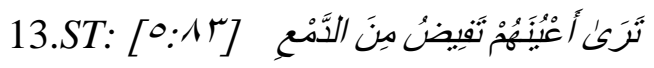

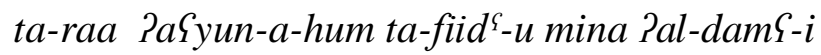

2MSG-see.IPFV eyes-ACC-3PL 3FSG-overflow.IPFV-IND PRE-DEF-tears-GEN

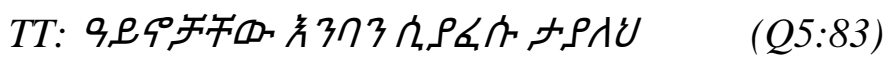

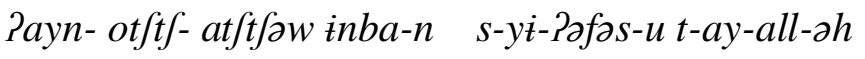

Eye-PL-3PL tear-ACC REL-overflow-3PL 2MSG-T-2MSG

TR: you see their eyes overflowing with tears (Q5:83)

The example given above (13) illustrates that the sentence in the source text used a feminine and singular verb تَفِيضُ (/ta-fiid'-u/) which means 'overflowing' preceded by a broken plural noun أَعْيَنَهُْ (/Pasyun-a-hum /) which means 'their eyes'. 


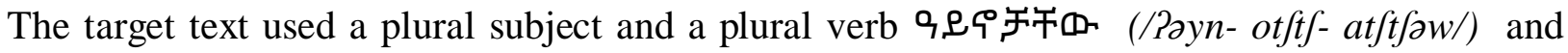

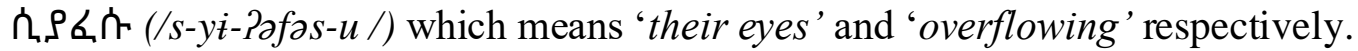

The above data (13) show that in the source text (Classical Arabic) if the subject of a sentence is a broken plural noun, its following verb may be put in a feminine and singular form. Therefore, in that case, there may not be a strict agreement in number between the subject and the verb. However, in the target text (Amharic), there is strict agreement in number and gender between the subject and the verb. That is, the target text used a plural subject and a plural verb. This shows number and gender shifts.

(n) The shift from a feminine and singular demonstrative pronoun + a feminine and plural noun in Arabic into a plural demonstrative pronoun + a plural noun in Amharic

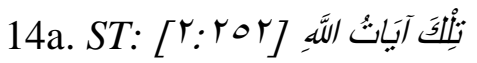

tilka ?aay-aat-u Pallaah-i

DEM.FSG verse-FPL-NOM Allah-GEN

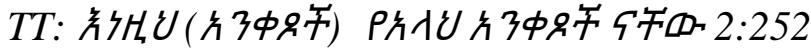

innazih (Pank's'-otftf) yo-Pallah ank's'- otft $n$ - atftfaw

DEM.PL (verse-PL) POSS-Allah verse-PL COP.PRF-3PL

TR: These are the verses of Allah 2:252

The example given above (14a) illustrates that the sentence in the source text used a feminine and singular demonstrative pronoun تِلْ (/tilka /) which means 'this' followed by a feminine and plural noun complement آَياتُ الَّهِ (/Paay-aat-u Pallaah-i /) which mean 'verses of Allah'.

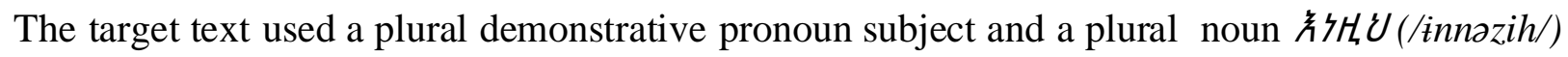
and P方オU 方 respectively.

14b.ST: [بْلْلَكَ آبَاتُ اللَّهِ 
tilka Paay-aat-u Pallaah-i

DEM.FSG verse-FPL-NOM Allah-GEN

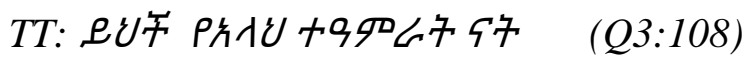

yih-tft yo-?allah to?amr-at $n$-at

DEM-F POSS- Allah sign-PL COP.PRF-3FSG

TR: These are the verses of Allah. (Q3:108)

The example given above (14b) illustrates that the nominal sentence in the source text uses a feminine and singular demonstrative pronoun feminine and plural noun complement آيَاثُ اللَّهِ (/Paay-aat-u Pallaah- /) which means 'verses of Allah'.

The target text uses a singular demonstrative pronoun subject and a plural complement noun $\mathscr{U}$ 年

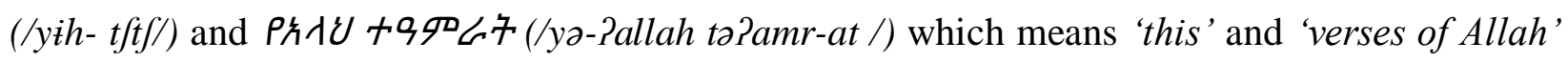
respectively.

The above data (14a) show that in the source text (Classical Arabic) if the complement of a nominal sentence is a feminine and plural noun, its preceding demonstrative pronoun subject may be put in a feminine and singular form. Therefore, in that case, there may not be a strict agreement in number between the subject and the verb. However, in the target text (Amharic), there is strict agreement in number and gender between the demonstrative pronoun and the noun that follows it. That is, the target text used a plural demonstrative pronoun and a plural noun. This shows number and gender shifts. However, in (14b), the translators employed a feminine and singular demonstrative pronoun followed by a plural noun in the target text. So, there is no agreement in number between the demonstrative pronoun and the noun that follows it. And, such is not allowed. This shows sometimes the translators adhere to the source language structure and violate the target language structure.

(o) The shift from a feminine and singular demonstrative pronoun + a broken plural noun in

Arabic into a plural demonstrative pronoun + a plural noun in Amharic 


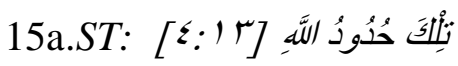

tilka ћuduud- u Pallaah-i

DEM.FSG limits-NOM Allah-GEN

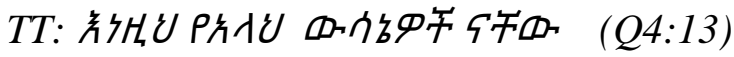

innazih yo-Pallah wussane- otft $n$-atft $\partial w$

DEM.PL POSS-Allah limit-PL COP.PRF-3PL

TR: These are the limits [set by] Allah (Q4:13)

The example given above (15a) illustrates that the nominal sentence in the source text used a feminine and singular demonstrative pronoun تِّن (/tilka/) which means 'this' followed by a broken plural noun as complement حُدُودُ اللَّهِ (/huduud-u Pallaah-i /) which mean 'the limits of Allah'.

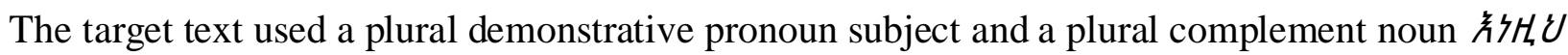

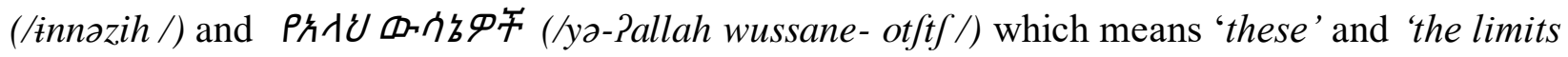
of Allah' respectively.

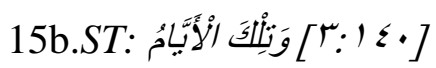

wa-tilka ?al-?ayyam-u

CONJ-DEM.FSG DEF- days-NOM

$T T:$ 写第390 中5年 $\quad(Q 3: 40)$

$y i h-t \int t \int-n-m \quad k$ ’on-at

DEM.SG-F-ACC-CONJ day-PL

TR: these days $(Q 3: 40)$

The example given above (15b) illustrates that the noun phrase in the source text uses a feminine

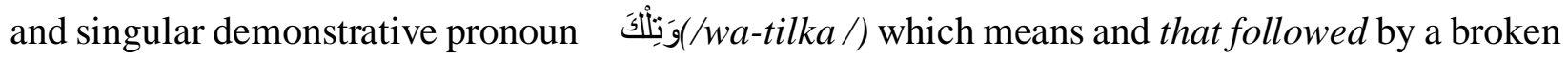

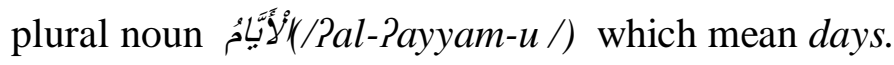


The target text uses a singular demonstrative pronoun and a plural noun $e$ 写军390(/yih- t $\int t \int-n-m$ /) and $\boldsymbol{\phi \zeta 7}$ (/k’on-at/) which mean 'this' and 'day's respectively.

The above data (15a) shows that in the source text (Classical Arabic) if the noun of the noun phrase or the nominal sentence is a broken plural noun, its preceding demonstrative pronoun may be put in a feminine and singular form.

Therefore, in that case, there may not be a strict agreement in number and gender between the demonstrative pronoun and the noun. However, in the target text (Amharic), there is strict agreement in number and gender between the demonstrative pronoun and the noun that follows it. That is, the target text used a plural demonstrative pronoun and a plural noun. This shows number and gender shifts. However, in (15b), the translators employed a feminine and singular demonstrative pronoun followed by a plural noun in the target text. So, there is no agreement in number between the demonstrative pronoun and the noun that follows it. And, such is not allowed. This shows sometimes the translators adhere to the source language structure and violate the target language structure.

(p) The shift from a feminine and dual noun + a feminine and dual verb in Arabic into a plural noun + a plural verb in Amharic

16a.ST:

fii fi?at-ayni Piltaqa-t-aa

PRE army.F-GEN.DU meet.PRF-F-DU

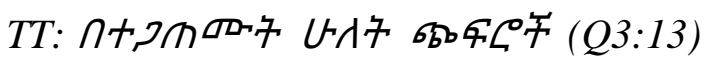

bə-yว-togat'am-ut hulat tf'ifr-otft

PRE-REL-meet.PRF-PL two army-PL

TR: in the two armies which met (Q3:13) 
The example given above (16) illustrates that the clause in the source text uses a feminine and dual

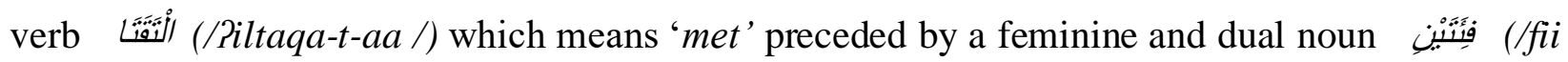
fi?at-ayni /) which means 'two armies'.

The above data (16) show that in the source text (Classical Arabic) if a verb follows a feminine and dual noun, it must be put in a feminine and dual form. Therefore, in that case, there is a strict agreement in number and gender between the subject and the verb. However, in the target text (Amharic), these feminine and dual noun and verb have been shifted into plural subject and verb for Amharic has no dual number. It does not also make distinction between masculine and feminine in the formation of plural nouns. Therefore, this shows both number and gender shifts.

(q)The shift from a masculine and dual subject + a masculine and dual verb in Arabic into a plural subject + a plural verb in Amharic That is, the shift from masculine and dual verbs and nouns into plural verbs and nouns.

17.ST: [0:1.V] فَآخَرانِ يُهُوَمَانِ

$$
\begin{aligned}
& \text { fa-Paaxar-aani ya-quum-aa-ni } \\
& \text { CONJ-other-NOM.DU 3- stand.IPFV-DU.IND }
\end{aligned}
$$

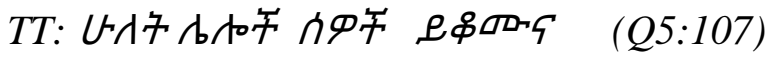

hulat lel- otft saw otft yit-k'om-u-nna

two other-PL man-PL 3- stand.IPFV-PL-CONJ

TR: let two others stand $(Q 5: 107)$

The example given above (17) illustrates that the clause in the source text uses a masculine and dual verb يَقْوَّان (Yya-quum-aa-ni/) which means 'stand' preceded by a masculine and dual noun فَآَخَران (/fa-Paaxar-aani/) which means 'two others'.

The target text uses a plural noun and a plural verb U and $e \& \square \square \neg\left(/ y \dot{i}-k^{\prime} o m-u-n n a /\right)$ which mean respectively. 
The above data (17) show that in the source text (Classical Arabic) if a verb follows a masculine and dual noun or pronoun, it must be put in a masculine and dual form. Therefore, in that case, there is a strict agreement in number and gender between the subject and the verb. However, in the target text (Amharic), these masculine and dual noun or pronoun and verb have been shifted into plural subject and verb for Amharic has no dual number. It does not also make distinction between masculine and feminine in the formation of plural nouns. Therefore, this shows both number and gender shifts.

(r) The shift from a collective feminine noun + a feminine and singular adjective in Arabic into a plural adjective or plural relativized verb + a plural noun in Amharic

$$
\begin{array}{r}
\text { 18.ST: [r.l r ] } \quad \text { Pummat-an Muslim-at-an } \\
\text { Nation.F-ACC Muslim-F-ACC }
\end{array}
$$

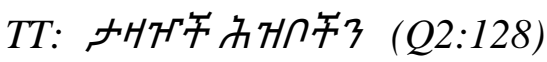

$$
\text { tazaz-otft } h \dot{z} z b-o t \int t-n
$$

submissive-PL nation-PL-ACC

TR: a Muslim nation (Q2:128)

The example given above (18a) illustrates that the noun phrase in the source text uses a collective noun

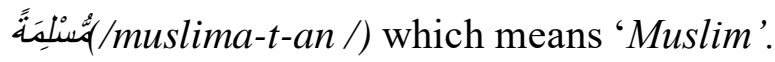

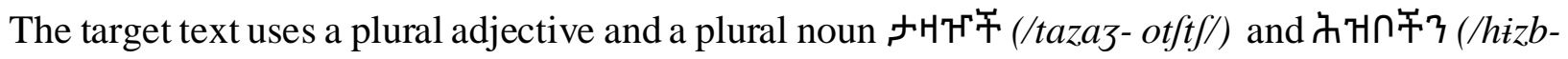
otftf-n/) which means 'the submissive' and 'nations' respectively.

The above data (18) show that in the source text (Classical Arabic) if the noun of a noun phrase is a collective feminine noun, its following adjective may be put in a feminine and singular form. Therefore, in that case, there is a strict agreement in number and gender between noun and its adjective. However, in the target text (Amharic), these a collective feminine noun and a feminine 
and singular adjective have been shifted into plural adjective and noun. Therefore, this shows both number and gender shifts

19.ST: $[r \cdot: r \wedge]$

li-qawm-in ya-Sqil-uu-na

PRE-people-GEN 3- use reason. IPFV-SBJMPL-IND

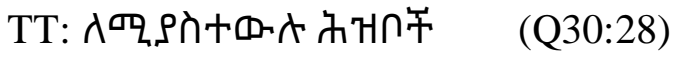

la- yəm-yi-astawl-u hizb-otft $\int$

PRE-REL-3- use reason-PL people-PL

TR: for a people who use reason $\quad(Q 30: 28)$

The example given above (19f) illustrates that the clause in the source text uses a masculine and plural verbs

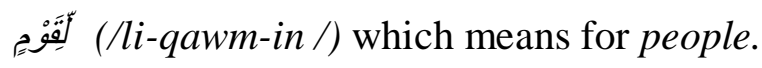

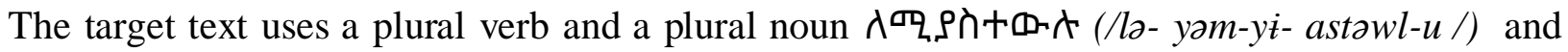

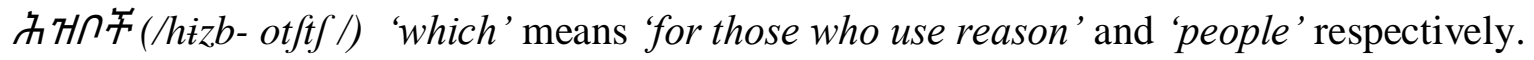

The above data (19) show that in the source text (Classical Arabic) if a verb follows a collective subject, it may be put in a masculine and plural form. Therefore, in that case, there may not be a strict agreement in number and gender between the noun and the verb. However, in the target text (Amharic), there is strict agreement in number and gender between the noun and the verb. That is, the target text used a plural verb and a plural noun. This shows number and gender shifts.

20.ST: :

wa-in-t'aaPifat-aani min Pal-muৎmin-iina Piqtatal-uи

CONJ-COND-faction. F-NOMDU PRE DEF-believer-GEN fight.PRF-3MPL

fa-Pa s'liћ-uи bayna-humaa 
CONJ- make settlement. IMP-2MPL PRE-3DU

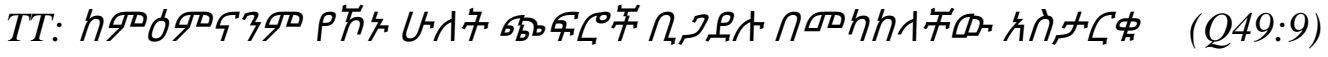

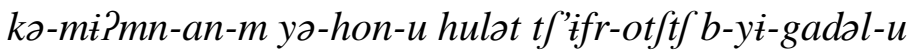

PRE-believer-PL-CONJ REL-COP.PRF-PL two faction REL-3-fight.IPFV-3PL

bamakakal- atfţaw astark'-u

PRE-POSS3PL make settlement.IMP -2PL

TR: And if two factions among the believers should fight, then make settlement

between the two.(Q49:9)

The example given above (20a) illustrates that the clause in the source text used a masculine and

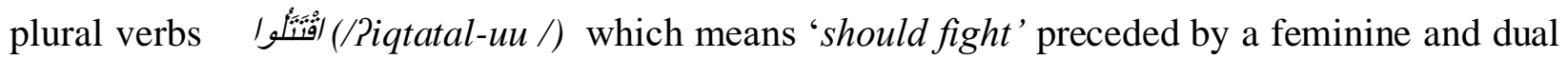

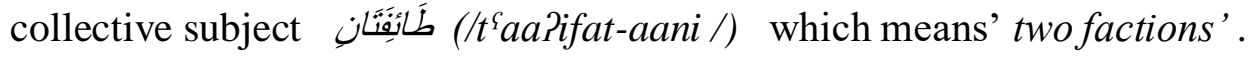

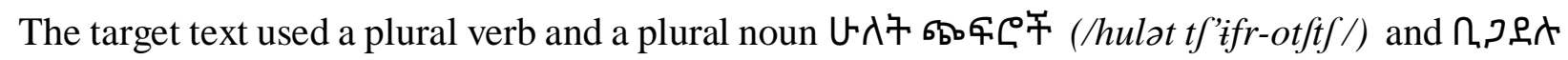
(/b-yi-gadal-u/) which mean means 'two factions' and 'should fight' respectively.

The above data (20) show that in the source text (Classical Arabic) if a verb follows a feminine and dual collective subject, the verb may be put in a masculine and plural form. Therefore, in that case, there may not be a strict agreement in number and gender between the noun and the verb. This type of construction is very rare in the Holy Qur'aan. However, in the target text (Amharic), there is strict agreement in number and gender between the noun and the verb. That is, the target text used a plural verb and a plural noun. This shows number and gender shifts.

\section{Conclusion}

Morphological shifts, number and gender shits, have been observed in the translation of the Holy Qur'aan from Arabic into Amharic. These shifts in number and gender have been made by the 
translators of the Holy Qur'aan from Arabic into Amharic to produce grammatical sentences in the target language structure. However, in some instances, the translators closely adhered to the source language structure and produced ungrammatical structures in the target language structure.

\section{References}

Baker, M. (1992). In other words: a coursebook in translation. London: Routledge

BayeYimam. (2000 EC).Amharic Grammar (in Amharic, 2nded.). Addis Ababa: EleniPublishers. Catford, J.C. (1965). A Linguistic Theory of Translation. London: Oxford University Press

Fischer, W. (1997).Classical Arabic. In Robert, Hetzrone.(Ed.). The Semitic Languages. New York: Routledge

Hatim, B. \& Mason, I. (1990). Discourse and the translator. Essex, England: Longman Group Limited, Longman House

Hetzrone,R.(2009).Semitic Languages.In Bernard,Comrie(Ed.) .The World's Major Languages. London and New York: Routledge

Hudson, G.(2009). Amharic. In Bernard,Comrie(Ed.) .The World's Major Languages.London and New York: Routledge

Jackobson, R. (1966). "On linguistic aspects of translation". In R. A.Brower (ed.) On

Translation; pp. 232-239.

Leslau,W. 1995. Reference Grammar of Amharic. Wiesbaden: Harrassowitz.

MuhammadThani Habib and Sayyid Muhammad . (1997). QiddusQur'aan (Amharic). Ethiopia, Addis Ababa. Alnejashi Islamic Organization

Munday, J. (2001). Introducing translation studies. London: Routledge.

Ryding, K. C. (2005). A Reference Grammae of Modern Standard Arabic. Cambridge: Cambridge University Press. 
Saheeh International.(1997).Translation of the Meaning of the Qur'aan in English Language.Saudi Arabia,Riyadh.Abul Qasim Publishing House.

Vinay, J-P. and J. Darbelnet (1995). Comparative Stylistics if French and English: a Methodology for Translation. Translated and edited by Juan C. Sager and M. J. Hamel. Amesterdam and Philadelphia:John Benjamins Publishing Company.

Wright, W. (2005).Arabic Grammar.New York: Dover Publications 